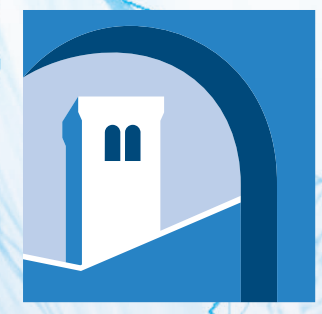

European

University

ROBERT

SCHUMAN

CENTRE FOR

ADVANCED

STUDIES

Issue 2019/12

July 2019
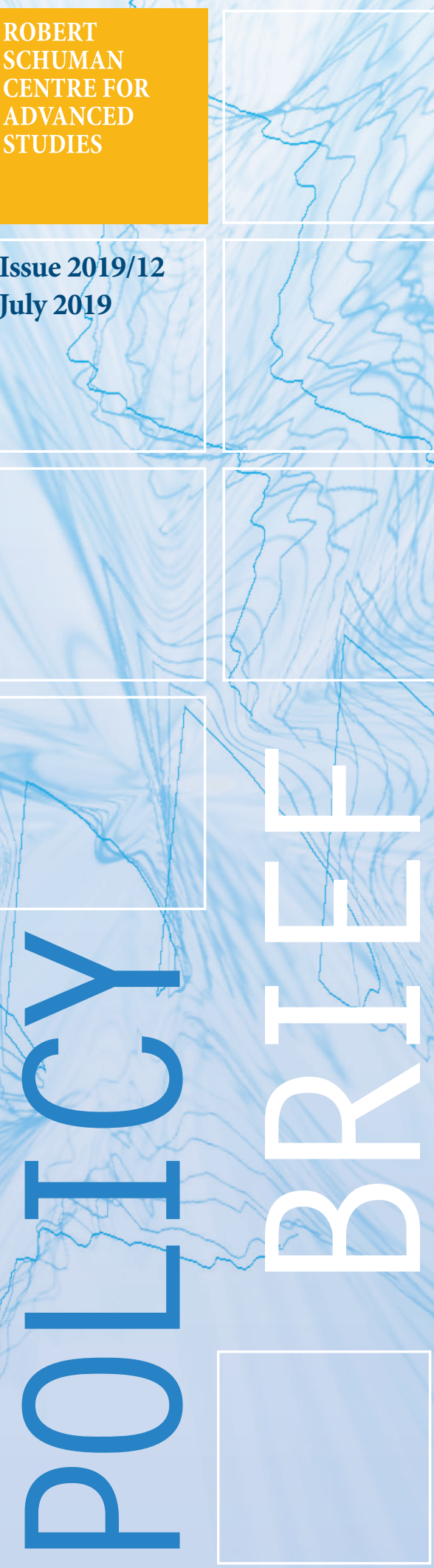

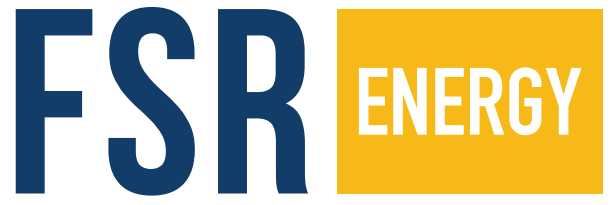

Florence School of Regulation

\title{
The European Union Energy Transition: Key Priorities for the Next Five Years
}

By Simone Tagliapietra (Bruegel), Georg Zachmann

(Bruegel), Ottmar Edenhofer (Potsdam Institute for Climate

Impact Research), Jean-Michel Glachant (Florence School

of Regulation), Pedro Linares (Universidad Pontificia

Comillas), Andreas Loeschel (University of Muenster),

\section{Highlights ${ }^{1}$}

- Over the last decade, the European Union has pursued a proactive climate policy and integrated a significant amount of renewable technologies - such as solar and wind - into the established energy system.

- These efforts have proved successful, and continuing along this pathway, increasing renewables and improving energy efficiency, would not require substantial policy shifts.

- The EU now needs a much deeper energy transformation to:

1. decarbonise in line with the Paris agreement

2. seize the economic and industrial opportunities offered by this global transformation

3. develop an EU approach to energy competitiveness and security, as the EU has neither the United States' shale potential nor China's top-down investment possibilities.

1. The authors would like to thank Laszlo Varro, Chief Economist of the International Energy Agency, for ideas and comments. 


\section{Policy Challenge}

A full-fledged energy transition is becoming economically and technically feasible, with most of the necessary technologies now available and technology costs declining. The cost of the transition would be similar to that of maintaining the existing system, if appropriate policies and regulations are put in place. In short, the EU could benefit from deep decarbonisation irrespective of what other economies around the world do. The transition can also be socially acceptable, if the right policies are put in place to control and mitigate the distributional effects of deeper decarbonisation. The time to act is now, because energy is a rigid system in which infrastructure and regulatory changes take a decade to be fully implemented, while competition is not sleeping - as Chinese solar panels and the rise of the electric vehicles industry clearly show. Policy choices made up to 2024 will define the shape of the EU energy system by 2050 .

\section{Setting the Right Energy Priorities for the new EU Institutional Cycle}

The new members of the European Parliament and European Commission who start their mandates in 2019 should put in place major policy elements to unleash the energy transition. Political capital is as always - limited, but four priorities are crucial to foster the EU energy transition: i) adopt transformative policies to decarbonise the transport sector; ii) prepare the electricity system for a substantial increase in renewables ${ }^{1}$, at acceptable cost and without compromising security; iii) strengthen the EU's comparative advantage in low-carbon technologies; and iv) foster the decarbonisation of industry and buildings.

The deep decarbonisation of electricity, transport, industry and buildings is an environmental imperative for Europe, and a unique economic opportunity. Decarbonising the European economy would make a significant contribution to the fight against global

\section{Four Priorities up to 2024 to Foster the EU Energy Transition}
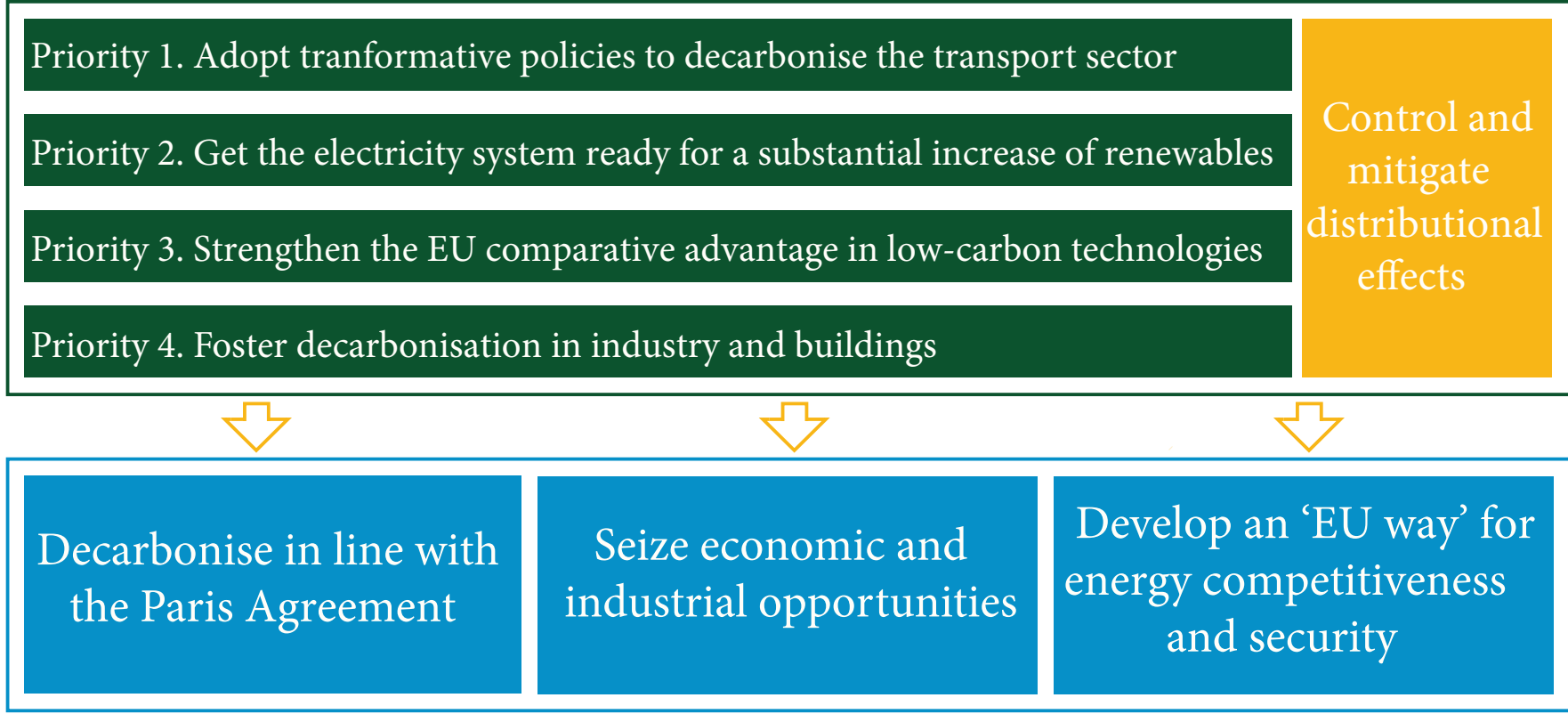

1. Over the last decade, renewables have become substantially more important in the EU energy mix. In 2017, the share of energy from renewable sources in EU gross final energy consumption reached 17.5 percent, up from 8.5 percent in 2004 (Eurostat, 2019). 
warming, as well as cleaning-up the air European citizens breath every day. Air pollution continues to be an invisible killer in Europe, causing each year almost half a million premature deaths (European Environment Agency, 2018a). Decarbonising the European economy also signifies investing in the industries of tomorrow. Europe has the potential to be a global leader in the manufacture of products such as wind turbines, electric cars and new-generation batteries. Investing in these industries can ensure the European manufacturing system's longterm economic competitiveness and sustainability ${ }^{2}$.

Decarbonisation policies should be carefully crafted because without extensive consideration of their distributional consequences there is a risk of social backlash $^{3}$. Avoiding this risk is possible, but it is crucial that the EU and national governments properly assess the distributional effects of their energy and climate policies, and take adequate measures to address them (Tagliapietra and Zachmann, 2018). This also applies to carbon pricing: the gap between actual prices and those required to achieve ambi- tious climate change mitigation could be closed by promoting public acceptance of carbon pricing through the effective use of the substantial revenues raised (Klenert et al, 2017).

Key policy priorities to foster the EU energy transition

Priority 1: Adopt Transformative Policies to Decarbonise the Transport Sector

Between 1990 and 2016, the EU's greenhouse gas emissions decreased significantly in all sectors with the exception of transport, which saw a 20 percent increase (European Environment Agency, 2018b) (Figure 1). Transport is thus becoming a key obstacle to EU decarbonisation. A particular focus should be placed on decarbonising road transport because it is responsible for more than 70 percent of overall transport emissions. Decarbonising road transport would also improve air quality in cities, which remains a fundamental challenge for better public health in Europe. All this should be done

Figure 1: EU Greenhouse Gas Emissions by Sector, 1990-2016

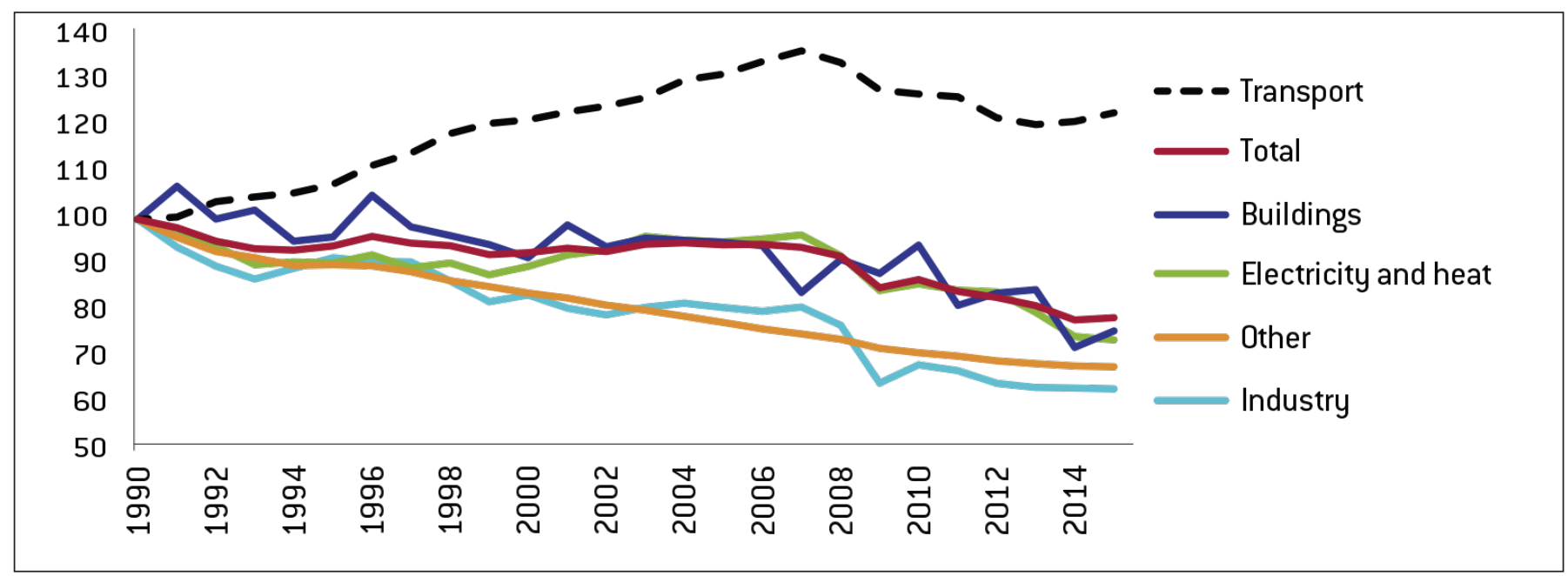

Source: Bruegel based on European Environment Agency (2018). Note: $1990=100$.

2. See Fredriksson et al (2018) for an in-depth discussion of the case of electric vehicles.

3. As illustrated by France's 'Gilets jaunes' movement, which kicked-off when the government announced its intention to rise fuel prices for environmental reasons, and then rapidly targeted overall high cost of living, claiming that a disproportionate burden of the government's tax reforms were falling on the middle classes. 
by assessing and addressing the distributive effects of transport decarbonisation policies, notably by taking into account that countries are made up of regions and constituencies with varying characteristics, including large semi-rural territories populated by low-income individuals deprived of public transport options and heavily sensitive to direct/indirect transport taxation (Zachmann, et al, 2018; Danesin and Linares, 2018).

To achieve the EU vision of a carbon-neutral economy by 2050 (European Commission, 2018), much stronger policies are thus required for transportation. Otherwise, under current policies, transport emissions might well exceed 1990 levels by 15 percent in 2050 (European Environment Agency, 2016).

Decarbonisation of transport will involve a range of policies. First, to replace the kilometres travelled by road vehicles, public transport, alternative transport modes such as walking and cycling, and more integrated modes of mobility should be promoted. New mobility such as 'mobility-as-a-service' can be enabled by ongoing developments in digital technologies. For instance, smartphone apps can allow information about transportation services from public and private providers to be better combined through a single gateway that creates and manages the trip, for which users can pay via a single account. New approaches could help overcome a major comparative disadvantage of public transport - the longer door-to-door travel times - which mainly arise from the first and the last mile in the transport chain.

The environmental impact of freight transport could be reduced by promoting a switch from road to rail and maritime, and including the environmental cost of transport in the final purchase price of goods. To unleash the enormous decarbonisation potential of these options, new policies are needed, including economic incentives such as congestion charges, public investment in railways and urban public transport, and new approaches to urban planning and development licencing. For aviation, modernisation of airport operations and air traffic control can deliver major efficiency gains. It should also be noted that very busy European air routes, such as Berlin to Frankfurt or Paris to Amsterdam, are suitable for international high-speed trains.

A second approach to the decarbonisation of transport is promotion of clean vehicles. The average age of the private car fleet in the EU is 7.5 years. This has been increasing since 2000, and in many EU countries this age even reaches 10 years (European Environment Agency, 2018c). The average car in Europe is, typically, high-emitting. Policies should therefore promote the accelerated substitution of the existing fleet by new, more advanced, low-emitting cars. From an economist's point of view, the first option would be to internalise fully into fuel prices the external costs of transport emissions, to disincentivise the use of older cars. However, public protests over fuel prices have shown that the political economy of these measures is very complex.

A combination of policies is therefore required, including carrots and sticks, starting from the key EU policy tool in the field: emission standards. In December 2018, the EU reached an agreement to reduce per kilometre carbon dioxide emissions from new cars by 37.5 percent by 2030 compared to 2021 (European Council, 2018). This represents a positive step, but it not enough to ensure the deep decarbonisation of the sector by 2050 . Other tools to phase-out polluting cars could include: i) gradual, long-term increases in fuel taxes that internalise fully external costs (including congestion charges) but give consumers time to adapt; ii) higher registration taxes that deter consumers from buying high-polluting cars; and iii) limitations on high-polluting vehicles accessing metropolitan areas. To foster this transition and ensure its social acceptability, the following measures could be adopted: i) subsidies that help low-income consumers buy new cars and scrap their old ones; ii) policies that support the deployment of clean public transport (which may be crowded out 
by car-sharing options); and iii) R\&D support for alternative vehicles.

Electric vehicles have emerged as a promising option to decarbonise the energy input into transportation. With smart charging, electric vehicles might also add additional flexibility to the power system, and thus contribute to the further integration of even greater wind and solar energy production. But other technologies might also contribute to this decarbonisation, including lower-emission combustion vehicles in the short term or hydrogen in the longer term. EU policy should be flexible enough to be able to take advantage, in a cost-effective way, of all the alternatives available.

For long-distance and heavy transport, technological uncertainty is far greater - not to mention maritime and air transport. In these cases, various options could contribute to decarbonisation, including advanced biofuels, green gas and synthetic fuels.
Priority 2: Prepare the Electricity System for a Substantial Increase in Renewables

In the EU, most of the expansion of renewable energy generation arises from utility-scale projects. Wind is more important in Europe than solar, and for wind the average project size is increasing. The most promising developments in recent years have been the technology and cost breakthroughs related to offshore wind, which have made possible really large-scale developments. Progress has been made in integrating utility-scale renewables, but it is still an unfinished journey: transmission needs to be expanded both onshore and offshore, more flexibility needs to be added and ultimately a better market design is needed.

Furthermore, the European electricity sector is on the verge of structural change, towards more digitalisation and decentralisation. The last fundamental change in the EU energy industry was the estab-

Figure 2: The EU Long-Term Vision for Climate Neutrality: Fuel Mix in Gross Energy Consumption

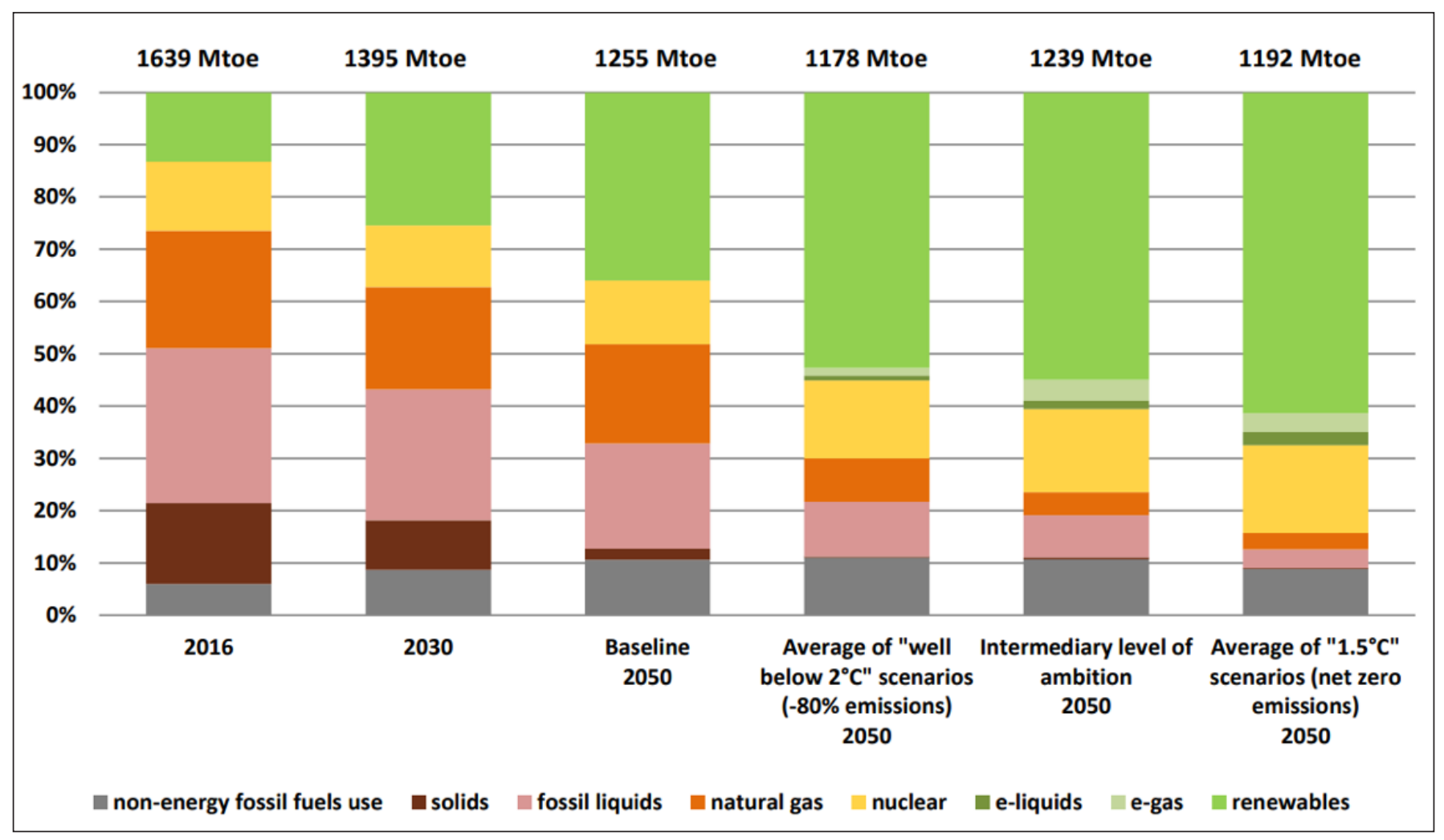

Source: European Commission (2018). Note: numbers above columns show gross inland consumption in million tonnes of oil equivalent. 
lishment of wholesale markets in the 1990s. That change, together with the entry of new players and new technologies ${ }^{4}$, required new common EU rules on efficiency, competition and security. The European electricity transmission industry reorganised accordingly, creating a 'smart grid $1.0^{\prime 5}$ to make all this work.

The ambitious EU vision of a carbon-neutral economy by 2050 calls for new fundamental changes, involving notably the greening of all the supply (Figure 2), activation of all demand-side management solutions, reviewing the stock of appliances, engines and their standards, sharing of all the assets, codes and data. This can only be achieved with a digitalised and decentralised energy system. Greater decentralisation and digitalisation would foster renewable energy deployment in a more efficient and cost-competitive way.

In this context, decentralisation of the energy sector would happen in various areas and for different reasons. Renewables generation would bring down the size of generating units: a nuclear power plant can have a capacity of 2 gigawatts and coal or natural gas-fired power plants a capacity of several hundred megawatts, but the capacity of an onshore wind turbine averages to 3 megawatts and the capacity of a solar panel amounts to some kilowatts. A similar transformation would occur on the demand side, where operators would aggregate kilowatt units of consumption to enter the wholesale market. Decentralised generation, aggregated demand and individual storage would take place 'behind the meter', in other words in a domestic or small-scale context, such as rooftop solar panels generating electricity for domestic use or batteries used to power electric cars. These domestic appliances are thus not covered by traditional energy regulation (Glachant and Rossetto, 2018).
The EU should act to accelerate this convergence between decentralisation and digitalisation. This should primarily happen in the distribution system, which is the place where the numerous distributed actions, behind and beyond the meter, physically interact by combining on a local level consumption, storage and generation. The distribution system should become an open platform, through which the various decisions of the multiple players can interact in a transparent and flexible manner.

Such an open platform would require a common distribution operation code, focusing on connected electricity devices, to allow a more flexible flow of electricity. Secondly, it would need a framework for common data coding and sharing, offering protection from fragmentation, cyber threats or dominance abuse. A third layer would be the tariffs charged by the distribution platforms, but this might be left entirely to national legislation, with a safeguard in EU competition law against abuse of dominant position by any distribution platform.

As decentralisation and digitalisation accelerates, each European country would be free to pick the kind of industry arrangement it prefers to deliver the high EU decarbonisation target. The options would be: i) A takeover by the dominant tech companies (such as Google), which would become operators of national distribution platforms; ii) Transformation of the existing grid operators into digital companies; iii) A blossoming of start-ups that would reinvent the energy sector; iv) The growth of distributed solutions such as energy communities.

Whatever choice each member state makes, the EU will need to put in place a pan-European framework that establishes a coherent multi-level architecture for data exchange and power-flow operation. This will enable the proper interaction of transmission

4. For example, combined cycle gas turbine plants.

5. Smart grids and smart meters ' 1.0 ', for instance, allow distribution companies and energy suppliers to reduce the cost of metering consumption and to detect electricity thefts better. They do not create a universal, interconnected space of operation, and - more importantly - they do not offer radically new services or personalised options to consumers. 
and distribution networks, microgrids and communities, smart buildings and the Internet of things (Schmitt, 2019).

\section{Priority 3: Strengthen the EU's Comparative Advantage} in Low-Carbon Technologies

The Paris Agreement should accelerate the global transition to a low-carbon economy. Global investment in low-carbon technology sectors - driven by investment in renewable electricity generation - has increased substantially and this trend is likely to continue. The strengthening of the EU's comparative advantage in low-carbon technologies would provide future job and growth opportunities. To achieve the EU's energy and climate policy targets, a wide range of low-carbon innovation is needed in different sectors including electricity, heat and cooling, transportation (see priority 1), the built environment and energy-intensive industrial sectors including iron and steel, metals, cement, pulp and paper and chemicals. Compared to the rest of the world, the EU is highly specialised in research and innovation in renewables and energy efficiency in buildings, and has increased its specialisation in renewable fuels, bioenergy, batteries and e-mobility (Zachmann and Kalcik, 2018) (Figure 3).

A country's competitive advantage in a particular sector often coincides with an R\&D specialisation in the same area. For example, countries that specialise in patenting in a certain low-carbon sector are also specialised in exporting in this sector. A number of factors can drive such $\mathrm{R} \& \mathrm{D}$ specialisation, including policy factors such as technologypush' measures including innovation subsidies, and 'demand-pull' measures including public procurement. Factors such as path dependencies also play an important role for both clean and dirty technologies. Past developments are less important for immature technologies and there is therefore an opportunity to shape the comparative advantage of many early stage low-carbon technologies. The major benefits associated with low-carbon innovation justify support throughout the innovation process from research to development and to deployment.

Public funding is particularly important in early stages of the innovation cycle. Public investment in low-carbon research and innovation and private investment (which accounts for about 80 percent of total expenditure) increased substantially in the last decade. This led to an overall increase in low-carbon technology patents (International Renewable Energy Agency, 2019). However, there are substantial differences between the sectors: private investment in the EU focuses mainly on batteries and e-mobility, renewable energy technologies and energy efficiency in industry. Renewable fuels and integrated and flexible energy systems attract larger shares of public investment. There is practically no EU R\&I investment in energy efficiency in buildings, in CCS or in the decarbonisation of industrial processes, even though these are potential game changers necessary for deep decarbonisation in the coming decades and thus should be R\&I priorities. It should be noted that it is mainly applied research done outside universities and national laboratories that is responsible for technology development in energy efficiency. Energy efficiency patents are positively associated with other non-energy innovations, and so general policies to promote innovation will also foster energy conservation inventions (Rexhäuser and Löschel, 2015).

Other examples for strategic $R \& D$ are potential breakthroughs in electrochemical or alternative storage technologies, the hydrogen economy or carbon capture and utilisation. A smart low-carbon transformation with low regulatory uncertainty and ambitious goals would increase the EU's competitiveness in the global marketplace. As well as basic research into immature technologies, learning-bydoing of near-commercial technologies can substantially drive down technology costs. Clear and stable market signals such as a minimum price on carbon that increases over time in all sectors of the EU economy will accelerate the deployment of these 
Figure 3: Actual and Potential Specialisation in Technology (x,y) and Exports (colour), 2012-14

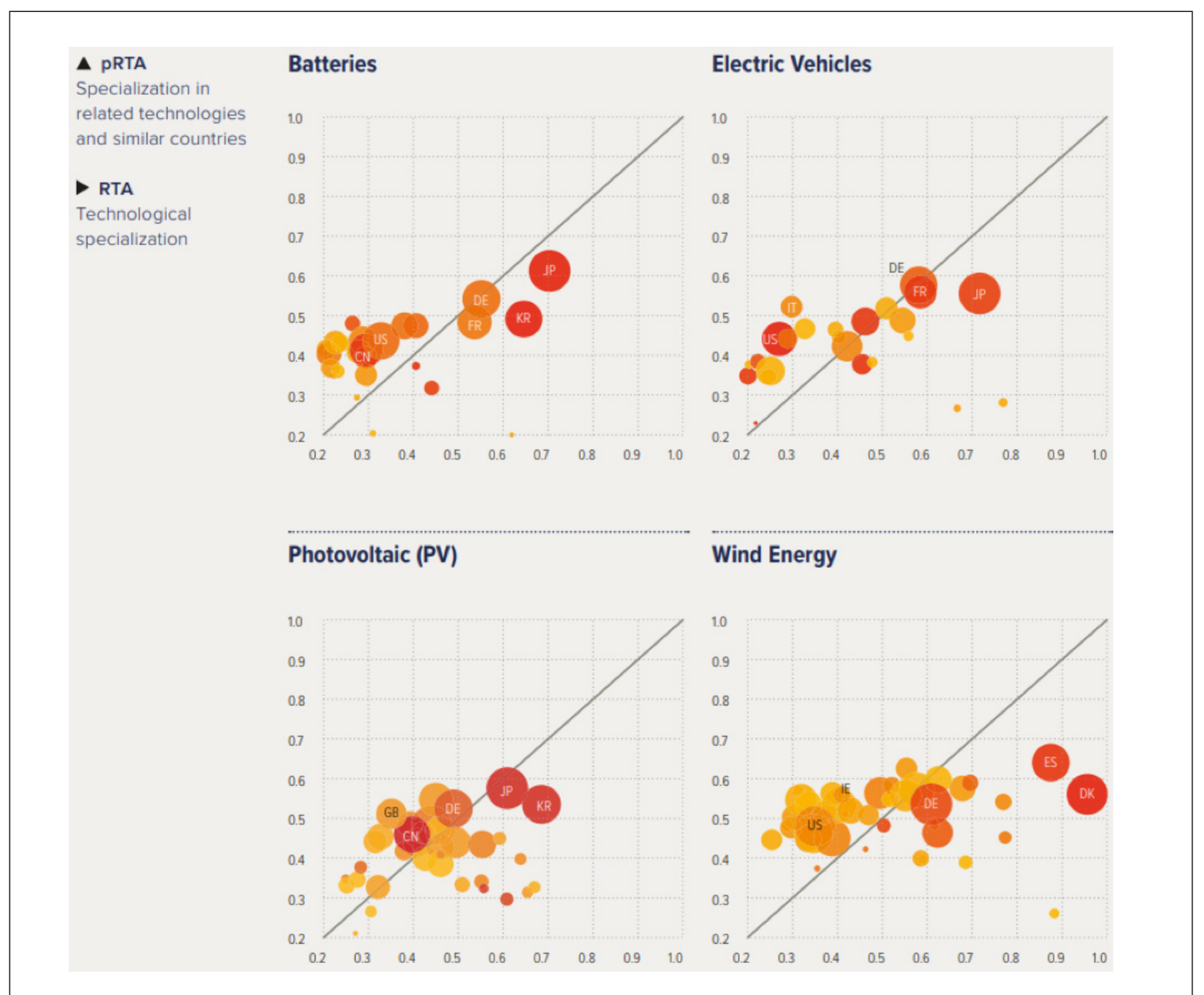

Source: Zachmann and Kalcik (2018). Note: the size of each country bubble indicates the number of patents in the sector. The darker a bubble, the greater a country's export specialisation. The bubble's position in the chart shows the relationship between current technological specialisation and potential technological specialisation. For countries that appear above the $45^{\circ}$ line, the indicator of potential specialisation exceeds that of current specialisation. Conversely, countries below the $45^{\circ}$ line have matured sectors in which they are already leading in terms of relative strength.

technologies. Renewable support schemes that focus on market integration of renewable energy generation would foster more flexible energy systems. Standards are essential for developing smart and flexible grid systems in the EU.
Priority 4: Foster the Decarbonisation of Industry and Buildings

Industry currently produces 25 percent of Europe's GHG emissions (European Environment Agency, 2018b), and is subject to the EU emissions trading system (ETS) and thus exposed to a carbon price. This, together with the fact that industry is gener- 
ally considered the most energy-efficient sector, has led to no particular policies being proposed beyond carbon trading for the decarbonisation of industry. However, there are four elements that would justify a more active stance: i) Industry does not feel the full impact of the carbon price because of the protective measures devised by the EU to prevent loss of competitiveness. Many industrial sectors still receive free carbon allowances; ii) The EU would like to see growth in the manufacturing sector; iii) When it comes to full decarbonisation, industry faces many more technical challenges than other sectors, in particular in relation to process emissions (that is, emissions not associated with energy use); iv) The circular economy will also induce a significant move in the EU industrial sector towards more recycling, which might be used also as a lever for decarbonisation.

Therefore, stronger policies are needed to promote the long-term decarbonisation of industry in Europe. Priority should be given to the following: i) Enhance recycling of materials, through the extension of the ecodesign directive (2009/125/EC), which should include stronger requirements for products to be more durable, repairable and easily recyclable; and by adding to producers' responsibility for the management of their end-of-life products; ii) Create markets for climate-friendly options: guaranteeing carbon prices for selected industrial processes; increasing green public procurement (using shadow carbon prices when evaluating offers, or setting limits on carbon intensity), harmonising labelling; or setting embedded carbon consumption taxes; iii) Create investment incentives while ensuring carbon leakage protection by spreading carbon pricing globally, adjusting carbon prices at the border and abandoning free allowance allocation, and applying consumption charges.

The building sector is generally regarded as difficult to decarbonise, notably because energy efficiency ambitions have proved challenging to achieve (European Commission, 2017). In this sector, similarly to transport, a robust energy efficiency effort will be the foundation of decarbonisation, with efforts led by the energy performance of buildings directive (2010/31/EU). For new buildings, Europe already has strong efficiency standards and performance is improving. Unfortunately, because of the slow turnover of the building stock, this is unlikely to be sufficient (Buildings Performance Institute Europe, 2018). The refurbishment rate of existing buildings needs to be scaled up by at least a factor of two and the average refurbishment needs to deliver deeper energy demand reductions. This will require a combination of efficiency standards, targeted financing policies and cooperation between central and municipal governments.

\section{Four Key Actions for the New EU Commissioners and Lawmakers}

The members of the European Parliament and European Commission who will start their mandates in 2019 have the historical task of unleashing the deeper transformation of the EU energy system in line with the Paris Agreement, while seizing the economic and industrial opportunities of this transformation and developing an EU approach to energy competitiveness and security. To summarise, we propose four key actions to move forward.

\section{Key Measures to Decarbonise the Transport Sector}

Replace the kilometres travelled by road vehicles by putting in place economic incentives such as congestion charges, public infrastructure investment in railways and urban public transport, while also refocusing urban planning and development licencing on sustainability. Promote the use of clean vehicles through a combination of stricter emissions standards and gradual increases in road fuel taxes to internalise fully the environmental costs of road transport. This notably implies increasing fuel taxes and car registration taxes for polluting vehicles. Other externalities including congestion and accidents also 
need to be addressed. To ensure social acceptability, targeted subsidies should be put in place to support low-income consumers in the transition. The EU and its members must work more on fairness and social acceptance in an accelerated transition, and should carefully study the positive results coming from field experiments and best practices, such the Copenhagen or Amsterdam smart city plans.

Key Measures to Prepare the Electricity System for a Substantial Increase in Renewables

Accelerate the convergence between decentralisation and digitalisation, notably by transforming the energy distribution grid into an open platform, via which multiple players (for example, domestic renewable energy producers, community renewable energy generators or storage provided by electric vehicles) could interact in a transparent and flexible manner. This can be started by defining a common distribution operation code and by creating a common data coding and sharing framework. The next step would be to create a pan-EU framework establishing a coherent multi-level architecture for data exchange and power-flow operation to enable the proper interaction of transmission and distribution networks, microgrids and smart buildings. This will help to further integrate utility-scale renewables, by expanding transmission both onshore and offshore, and by enhancing flexibility. The EU electricity market design should also be reformed, to make it fully supportive of a high renewables system.

\section{Key Measures to Strengthen the EU's Comparative Advantage in Low-Carbon Technologies}

Target public sector research and innovation funding at the early stages of the innovation cycle, notably in areas in which the EU has the potential to maintain or develop a comparative advantage - such as in renewables, energy efficiency in buildings, bioenergy, batteries and e-gas and e-liquids. Develop a predictable market environment for new low-carbon technologies to foster the emergence of a corresponding industrial ecosystem.

Key Measures to Foster Decarbonisation in Industry and Buildings

In industry, promote the recycling of materials, also by extending producers' responsibility for the management of their end-of-life products. Create lead markets for climate-friendly options by guaranteeing carbon prices for selected industrial processes, increasing green public procurement and harmonising labelling. In buildings, make robust energy efficiency efforts, notably through a combination of efficiency standards, targeted financing policies and cooperation between central and municipal governments.

\section{References}

Buildings Performance Institute Europe (2018) Policy innovation for building renovation. How can policy innovation scale up the decarbonisation of the building stock in Europe?

Danesin, A. P. and Linares (2018) 'The relevance of the local context for assessing the welfare effect of transport decarbonization policies. A study for 5 Spanish metropolitan areas', Energy Policy 118: 41-57

European Commission (2017) '2017 assessment of the progress made by Member States towards the national energy efficiency targets for 2020 and towards the implementation of the Energy Efficiency Directive', $\operatorname{COM(2017)~} 687$ final

European Commission (2018) 'A Clean Planet for all. A European strategic long-term vision for a prosperous, modern, competitive and climate neutral economy', $\operatorname{COM}(2018) 773$ final

European Council (2018) 'CO2 emission standards for cars and vans: Council agrees its position', press release 

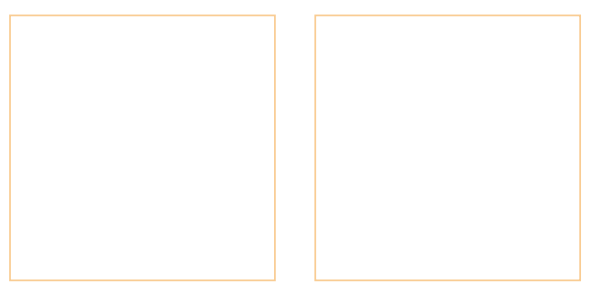

Eurostat (2019) 'Share of renewable energy in the EU up to $17.5 \%$ in 2017, News release 27/2019, 12 February,

European Environment Agency (2016) 'TERM 2016: Transitions towards a more sustainable mobility system', EEA Report No 34/2016

European Environment Agency (2018a) 'Air quality in Europe - 2018 report', EEA Report No 12/2018

European Environment Agency (2018b) 'Recent trends and projections in EU greenhouse gas emissions', EEA Briefing No 12/2018

European Environment Agency (2018c) 'Average age of the vehicle fleet'

Fredriksson, G., A. Roth, S. Tagliapietra and R. Veugelers (2018) 'Is the European automotive industry ready for the global electric vehicle revolution?' Policy Contribution 26/2018, Bruegel

Glachant, J-M. and N. Rossetto (2018) 'The Digital World Knocks at Electricity's Door: Six Building Blocks to Understand Why', Policy Brief 2018/16, Florence School of Regulation

International Renewable Energy Agency (2019) INSPIRE - International Standards and Patents in Renewable Energy

Klenert, D., L. Mattauch, E. Combet, O. Edenhofer, C. Hepburn, R. Rafaty and N. Stern (2017) 'Making Carbon Pricing Work', MPRA Paper No. 80943

Rexhäuser, S. and A. Löschel (2015) 'Invention in energy technologies: Comparing energy efficiency and renewable energy inventions at the firm level', Energy Policy 83: 206-2017

Schmitt, L. (2019) 'New digital architectures and platforms', in S. Nies (ed) The European Energy Transition. Actors, Factors, Sectors, Claeys \& Casteels, Deventer
Tagliapietra, S. and G. Zachmann (2018) 'What the "gilets jaunes" movement tells us about environment and climate policies', Bruegel Blog, 30 November

Zachmann, G. and R. Kalcik (2018) 'Export and patent specialization in low-carbon technologies', in S. Dutta, B. Lanvin and S. Wunsch-Vincent (eds) Global innovation index 2018, Cornell University, INSEAD and WIPO

Zachmann, G., G. Fredriksson and G. Claeys (2018) The distributional effects of climate policies, Blueprint 28, Bruegel 

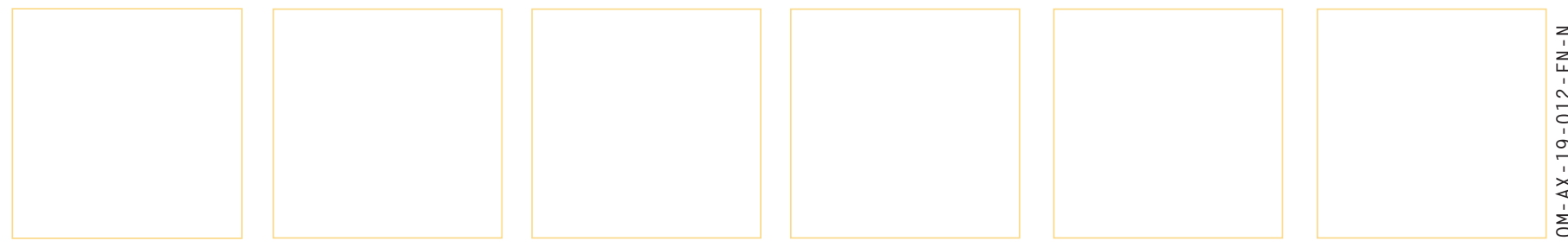

Florence School of Regulation

Robert Schuman Centre

for Advanced Studies

European University Institute

Via Boccaccio, 121

50133 Florence

Italy

\section{Contact:}

email: fsr@eui.eu website: fsr.eui.eu

\section{Robert Schuman Centre for Advanced Studies}

The Robert Schuman Centre for Advanced Studies, created in 1992 and directed by Professor Brigid Laffan, aims to develop inter-disciplinary and comparative research on the major issues facing the process of European integration, European societies and Europe's place in $21^{\text {st }}$ century global politics. The Centre is home to a large post-doctoral programme and hosts major research programmes, projects and data sets, in addition to a range of working groups and ad hoc initiatives. The research agenda is organised around a set of core themes and is continuously evolving, reflecting the changing agenda of European integration, the expanding membership of the European Union, developments in Europe's neighbourhood and the wider world.

\section{The Florence School of Regulation}

The Florence School of Regulation (FSR) was founded in 2004 as a partnership between the Council of the European Energy Regulators (CEER) and the European University Institute (EUI), and it works closely with the European Commission. The Florence School of Regulation, dealing with the main network industries, has developed a strong core of general regulatory topics and concepts as well as inter-sectoral discussion of regulatory practices and policies.

Complete information on our activities can be found online at: fsr.eui.eu 